\title{
Crystal Structure Determination of 5,6-Dibromoacenaphthene from X-ray Powder Diffraction Data
}

\author{
Nongnuj J aiboon* \\ Department of Chemistry, Fa culty of Science, Chula longkom University, \\ Bangkok 10330, Tha iland. \\ *Corresponding author, E-mail: nongnuj.j@chula.ac.th
}

Received 14 Feb 2001

Accepted 8J an 2002

\begin{abstract}
The new crystal structure of 5,6-dibromoacenaphthene has been successfully determined from X-ray powder diffraction data with monoclinic crystals, $P 2_{1} / \mathrm{n}, a=7.88$ (1) $\AA, b=11.64$ (1) $\AA, c=$ 11.62(1) $\AA, \beta=107.09(9)^{\circ}, V=1019.9(1) \AA^{3}$ and $Z=4$. Individual reflection intensities were extracted by means of Le Bail's method. The molecular structure of $\mathbf{1}$ was solved by direct methods and refined using the combination of least-squares and Rietveld methods. The final Rietveld refinement converged to the value of $R_{p}=0.114, R_{w p}=0.155$, Bragg $-R_{f}=5.28$ for 8532 data points and 933 extracted reflections collected in the $2^{\circ}<2 \theta<95^{\circ}$ range. The molecules have an interplanar $\pi-\pi$ interaction between the acenaphthene planes with the average distance of 3.57(9) $\AA$. M oreover, the molecular dimer-pairwise packing diagram has an unexpected straight stacking, as opposed to the usual lateral stacking normally occured in 5,6-dihaloacenaphthene.
\end{abstract}

KEYWORDS: Structure determination, X-ray powder diffraction, Rietveld Method, 5,6-dibromoacenaphthalene.

\section{INTRODUCTION}

X-ray single-crystal diffraction (XRSC) is the most powerful technique for determining crystal structures. Until recently, crystal structure determination from X-ray powder diffraction (XRPD) data was a challenging task. ${ }^{1}$ Crystal structures of organic compounds determined from $X$-ray powder diffraction data are rare. ${ }^{2}$ This paper reports a new crystal structure of 5,6-dibromoacenaphthene, which was determined from XRPD data using an ab initio method. Theab initio structure determination is the procedure of solving the phase problems without a preliminary model. This method is usually applied to classic inorganic compounds. ${ }^{3}$ In this technique, the powder diffraction data must be extracted into three-dimensional data in the same reciprocal lattice as the data collected from the XRSC technique using the full-pattern decomposed methods. After the data were extracted successfully, the phase problem was solved using the direct methods or the Patterson method. Finally, the model structure was refined using the least-squares and the full-pattern fitting methods (Rietveld method).

In this paper the crystal structure of the title compound was determined from X-ray powder diffraction data. Its topology, crystal packing and intermolecular interactions, namely a $\pi-\pi$ interaction, of the title compound were studied and were compared with the related compounds searched in the Cambridge Structural Database (CSD) ${ }^{4}$ In addition, the molecular dimer-pairwise packing diagram of the title compound has an unexpected straight stacking, as opposed to the usual lateral stacking diagrams, which normally occurred in 5,6dihaloacenaphthene.

\section{Materials and Methods}

\section{X-ray data collection}

The sample was gently ground in an agate mortar. The resulting powder was "sideloaded" into a sample holder, and was smoothed with a glass slide to reduce preferred orientation. The step-scanned diffraction data were measured on a Rigaku diffractometer using graphite monochromatized $\mathrm{Cu}-\mathrm{K}_{\alpha}$ radiation $(\lambda=1.5406 \AA)$ operating at $40 \mathrm{kV}$ and $30 \mathrm{~mA}$. The divergence slit size was $1 \mathrm{~mm}$ and the receiving slit was $0.1 \mathrm{~mm}$. The pattern was collected in the $2^{\circ}<$ $2 \theta<100^{\circ}$ range with a step size of $0.01^{\circ}$ and counting time of 10 seconds per step. The $\mathrm{K}_{\alpha 2}$ contribution was mathematically removed from the data. The 
pattern was indexed using TREOR90 programs ${ }^{5}$ on the basis set of the highest 20 observed lines. The best solution which indexed all the lines indicated a monoclinic unit cell with parameters a $=7.88(1) \AA$, $b=11.64(1) \AA, c=11.62(1) \AA, b=107.09(9)^{\circ}, V=$ $1019.9(1) \AA^{3}$. The systematic absences were consistent with the space group $\mathrm{P} 2 / \mathrm{n}(\mathrm{hOl} ; \mathrm{hH}=2 \mathrm{n}$, $\mathrm{h} 00 ; \mathrm{h}=2 \mathrm{n}, 0 \mathrm{k} 0 ; \mathrm{k}=2 \mathrm{n}, 00 \mathrm{l} ; \mathrm{l}=2 \mathrm{n})$.

\section{Structure solution and refinement}

Initially the powder pattern was refined by FULLPROF program ${ }^{6}$ using the following parameters; zero point error, background parameters (polynomial functions), peak shape profiles (Pseudovoigt coefficient) ${ }^{7}$, FWHM parameters and lattice parameters. In this stage no structural model was used in the refinement cycles. Individual reflection intensities were extracted by means of Le Bail's decompositions ${ }^{8}$ of which 933 individual reflections were extracted. This extracted data was then used to solve the structure by direct methods using SHELXS-97 for PC $^{9}$. The two bromine atomic positions were found from electron density maps; Br1 (0.1190, 0.9073, 0.3554), Br2 (0.4086, 0.9276,
0.2073), and were used as a starting structural model in the Rietveld refinement using FULLPROF. The individual intensities were re-extracted and a direct methods calculation was then recomputed until all non-hydrogen atoms were found. The model structure was refined using least squares method and difference Fourier maps. At the last step, all nonhydrogen atoms were found from difference F ourier maps, except for C 6 and $\mathrm{C} 12$ which had to be calculated from idealized rigid planar positions using SHELXL-9712. All non-hydrogen atoms, except Br1 and $\mathrm{Br} 2$, were refined with isotropic displacement parameters and $\mathrm{Br} 1$ and $\mathrm{Br} 2$ were refined with anisotropic displacement parameters. The atomic positions of $\mathrm{C} 1, \mathrm{C} 6$ and $\mathrm{C} 11$ were disordered and refined with fixed isotropic displacement parameters. All hydrogen atoms were placed in calculated positions and were refined with a riding model ${ }^{9}$ with $\mathrm{U}$ iso being $1.5 \mathrm{U}$ of of the $\mathrm{C}$-atoms to which they were attached. The final Rietveld refinement gave $\mathrm{Rp}=$ 0.114 and Rwp $=0.155$. The final Rietveld plot is shown in Fig 1. Crystallographic data and details of the Rietveld refinement are given in Table 1.

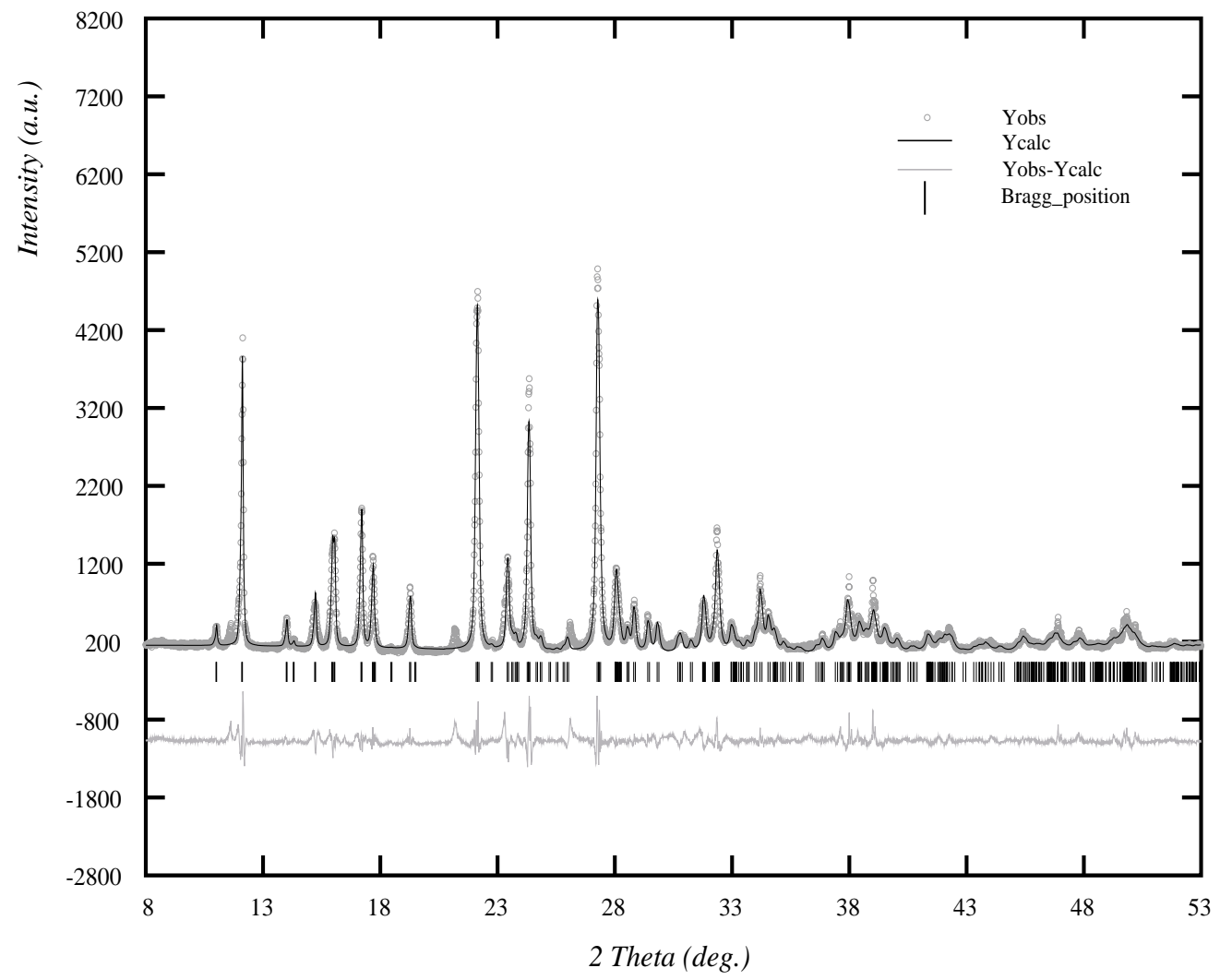

Fig 1. Experimental (0), calculated (solid line) and difference powder X-ray diffraction profiles for the Rietveld refinement of 5,6dibromoacenaphthalene. Reflection positions are marked. The calculated powder diffraction profile is for the final refined crystal structure. 


\section{Results AND Discussion}

The crystal structure of 5,6-dibromoacenaphthalene ( $\mathbf{1}$ ) was successfully determined from $X$-ray powder diffraction data. The drawing of this compound with atomic labeling is shown in Fig 2. Atomic positions for all non-hydrogen atoms, relevant bond distances and bond angles are given in Table 2 and Table 3, respectively. It should be noted that the structure determination of 1 from $X$ ray powder diffraction data was able to give only

Table 1. Crystallographic Data for 5,6-dibromoacenaphthalene $\left(\mathrm{C}_{12} \mathrm{H}_{8} \mathrm{Br}_{2}\right)$.

\begin{tabular}{ll}
\hline Formula weight & 312.02 \\
Crystal system & Monoclinic \\
Space group & $P 21 / n($ No.14) \\
$a$ & $7.88(1) \AA$ \\
$b$ & $11.64(1) \AA$ \\
$c$ & $11.62(1) \AA$ \\
$\beta$ & $107.09(1)^{\circ}$ \\
$V$ & $1019.9(1) \AA^{3}$ \\
$Z$ & 4 \\
$D_{c a l}$ & $2.023 \mathrm{~g} \mathrm{cm^{-3 }}$ \\
$\lambda\left(\right.$ Cu K $\alpha_{1}$, K $\left._{2}\right)$ & $1.54056,1.54433 \AA$ \\
Temperature $($ K) & 298 \\
Data range $\left(^{\circ}\right)$ & $2 \leq 2 \theta \leq 95$ \\
No. profile point & 8532 \\
No. parameters & 111 \\
Peak shape function & Pseudo-voigt \\
Background & Polynomial function \\
$R_{\text {exp }}$ & 0.066 \\
$R_{p}$ & 0.114 \\
$R_{w p}$ & 0.155 \\
\hline
\end{tabular}

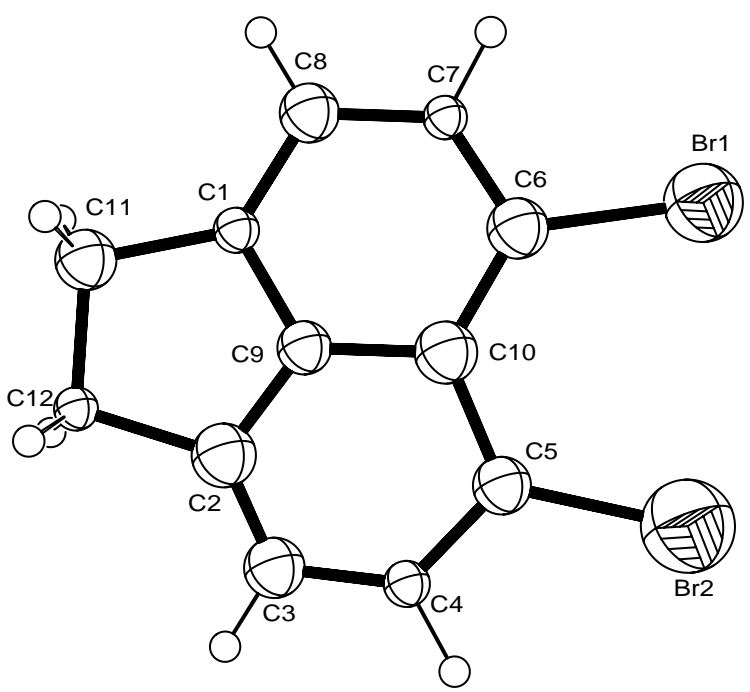

Fig 2. An ORTEP12 view of 5,6-dibromo acenaphthalene. average bond distances, overall topology, molecular conformations and crystal packing diagram.

Table 2. Atomic coordinates $\left(x 10^{4}\right)$ and equivalent isotropic displacement parameters $\left(\AA^{2} \times 10^{3}\right)$.

\begin{tabular}{lrrrr}
\hline Atom & $\boldsymbol{x}$ & $\boldsymbol{y}$ & $\boldsymbol{z}$ & $\boldsymbol{U}(\mathbf{e q})$ \\
\hline $\mathrm{Br}(1)$ & $1091(5)$ & $945(3)$ & $3492(3)$ & $67(2)$ \\
$\mathrm{Br}(2)$ & $4169(6)$ & $733(4)$ & $2100(4)$ & $94(2)$ \\
$\mathrm{C}(1)$ & $-1570(40)$ & $-2140(20)$ & $920(30)$ & $22(9)$ \\
$\mathrm{C}(2)$ & $490(40)$ & $-2220(30)$ & $-120(30)$ & $45(11)$ \\
$\mathrm{C}(3)$ & $1810(40)$ & $-1840(30)$ & $-400(20)$ & 40 \\
$\mathrm{C}(4)$ & $2890(30)$ & $-1040(20)$ & $310(30)$ & $23(10)$ \\
$\mathrm{C}(5)$ & $2570(40)$ & $-430(20)$ & $1250(20)$ & $16(10)$ \\
$\mathrm{C}(6)$ & $220(40)$ & $-320(20)$ & $2440(30)$ & 40 \\
$\mathrm{C}(7)$ & $-1280(40)$ & $-800(20)$ & $2550(20)$ & $21(10)$ \\
$\mathrm{C}(8)$ & $-2190(40)$ & $-1680(30)$ & $1840(30)$ & $38(11)$ \\
$\mathrm{C}(9)$ & $0(40)$ & $-1710(30)$ & $800(30)$ & $31(10)$ \\
$\mathrm{C}(10)$ & $940(40)$ & $-790(20)$ & $1520(20)$ & $12(9)$ \\
$\mathrm{C}(11)$ & $-2170(40)$ & $-3160(20)$ & $50(20)$ & 40 \\
$\mathrm{C}(12)$ & $-830(30)$ & $-3220(20)$ & $-650(20)$ & $21(9)$ \\
$\mathrm{C} 101$ & 367 & -1308 & 1098 & 10 \\
\hline
\end{tabular}

$\mathrm{U}(\mathrm{eq})$ is defined as one third of the trace of the orthogonalized Uij tensor.

Table 3. Bond lengths $[\AA]$ and angles $\left[{ }^{\circ}\right]$ for 5,6 dibromoacenaphthalene.

\begin{tabular}{llll}
\hline $\mathrm{Br}(1)-\mathrm{C}(6)$ & $1.91(3)$ & $\mathrm{C}(3)-\mathrm{C}(4)$ & $1.36(3)$ \\
$\mathrm{Br}(2)-\mathrm{C}(5)$ & $1.92(2)$ & $\mathrm{C}(4)-\mathrm{C}(5)$ & $1.39(3)$ \\
$\mathrm{C}(1)-\mathrm{C}(9)$ & $1.38(4)$ & $\mathrm{C}(5)-\mathrm{C}(10)$ & $1.47(3)$ \\
$\mathrm{C}(1)-\mathrm{C}(8)$ & $1.40(3)$ & $\mathrm{C}(6)-\mathrm{C}(7)$ & $1.35(3)$ \\
$\mathrm{C}(1)-\mathrm{C}(11)$ & $1.55(3)$ & $\mathrm{C}(6)-\mathrm{C}(10)$ & $1.46(3)$ \\
$\mathrm{C}(2)-\mathrm{C}(3)$ & $1.26(4)$ & $\mathrm{C}(7)-\mathrm{C}(8)$ & $1.37(3)$ \\
$\mathrm{C}(2)-\mathrm{C}(9)$ & $1.37(3)$ & $\mathrm{C}(9)-\mathrm{C}(10)$ & $1.43(3)$ \\
$\mathrm{C}(2)-\mathrm{C}(12)$ & $1.57(3)$ & $\mathrm{C}(11)-\mathrm{C}(12)$ & $1.52(3)$ \\
$\mathrm{C} 701-\mathrm{C}$ (101) & $3.91(2)$ & & \\
& & & \\
$\mathrm{C}(9)-\mathrm{C}(1)-\mathrm{C}(8)$ & $118(3)$ & $\mathrm{C}(7)-\mathrm{C}(6)-\mathrm{Br}(1)$ & $115(3)$ \\
$\mathrm{C}(9)-\mathrm{C}(1)-\mathrm{C}(11)$ & $108(3)$ & $\mathrm{C}(10)-\mathrm{C}(6)-\mathrm{Br}(1)$ & $128(2)$ \\
$\mathrm{C}(8)-\mathrm{C}(1)-\mathrm{C}(11)$ & $133(3)$ & $\mathrm{C}(6)-\mathrm{C}(7)-\mathrm{C}(8)$ & $125(3)$ \\
$\mathrm{C}(3)-\mathrm{C}(2)-\mathrm{C}(9)$ & $120(3)$ & $\mathrm{C}(7)-\mathrm{C}(8)-\mathrm{C}(1)$ & $120(3)$ \\
$\mathrm{C}(3)-\mathrm{C}(2)-\mathrm{C}(12)$ & $132(4)$ & $\mathrm{C}(2)-\mathrm{C}(9)-\mathrm{C}(1)$ & $113(3)$ \\
$\mathrm{C}(9)-\mathrm{C}(2)-\mathrm{C}(12)$ & $109(3)$ & $\mathrm{C}(2)-\mathrm{C}(9)-\mathrm{C}(10)$ & $125(3)$ \\
$\mathrm{C}(2)-\mathrm{C}(3)-\mathrm{C}(4)$ & $120(3)$ & $\mathrm{C}(1)-\mathrm{C}(9)-\mathrm{C}(10)$ & $122(3)$ \\
$\mathrm{C}(3)-\mathrm{C}(4)-\mathrm{C}(5)$ & $127(3)$ & $\mathrm{C}(9)-\mathrm{C}(10)-\mathrm{C}(6)$ & $118(3)$ \\
$\mathrm{C}(4)-\mathrm{C}(5)-\mathrm{C}(10)$ & $113(3)$ & $\mathrm{C}(9)-\mathrm{C}(10)-\mathrm{C}(5)$ & $115(3)$ \\
$\mathrm{C}(4)-\mathrm{C}(5)-\mathrm{Br}(2)$ & $122(2)$ & $\mathrm{C}(6)-\mathrm{C}(10)-\mathrm{C}(5)$ & $127(3)$ \\
$\mathrm{C}(10)-\mathrm{C}(5)-\mathrm{Br}(2)$ & $125(2)$ & $\mathrm{C}(12)-\mathrm{C}(11)-\mathrm{C}(1)$ & $105(2)$ \\
$\mathrm{C}(7)-\mathrm{C}(6)-\mathrm{C}(10)$ & $117(3)$ & $\mathrm{C}(11)-\mathrm{C}(12)-\mathrm{C}(2)$ & $104(2)$ \\
$\mathrm{C}(4)-\mathrm{C}(11)-\mathrm{C}(12)-\mathrm{C}(5)$ & $1(3)$ & & \\
\hline
\end{tabular}

Symmetry transformations used to generate equivalent atoms: $i$ : $-x,-y,-z$. 


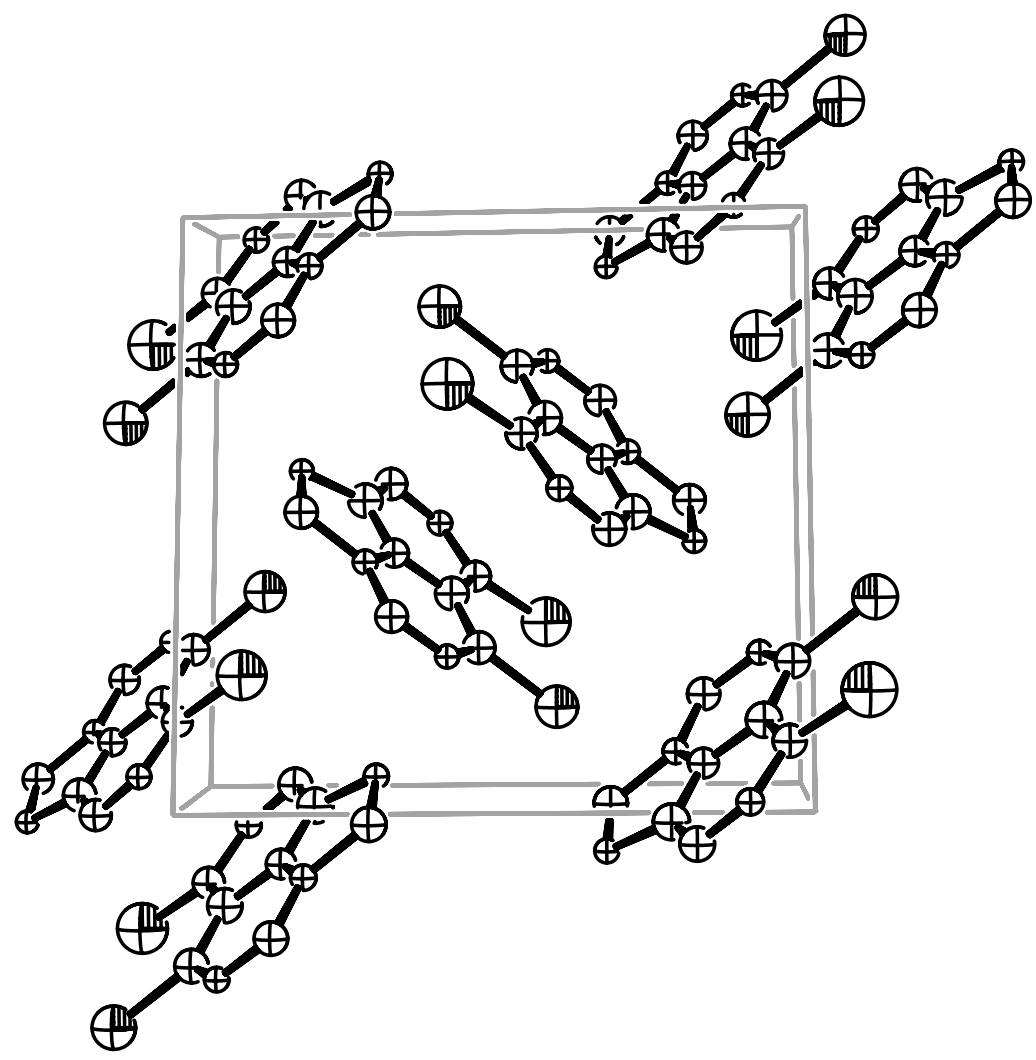

Fig 3. Molecular packing of 5,6-dibromoacenaphthalene along the a-axis, showing the $\pi$ - $\pi$ interaction between the acenaphthalene plans with the distance of $3.57(9) \AA$.

Comparison with 1,8-dibromonaphthene, in $\mathbf{1}$ the ethylene bridging the 1,2-positions has forced the 5,6-dibromoacenaphthene framework planar. Deviation of the acenaphthene carbon atoms from their least-squares planes ( $\mathrm{C} 1$ to $\mathrm{C} 10$ ) are in the range of $-0.07(2) \AA$ to $0.03(2) \AA$. The $\mathrm{C}-\mathrm{C}$ bond distances in the acenaphthene ring showed considerable variation, falling in the range of 1.34 (3) $\AA$ to 1.47 (3) $\AA$. These are corresponding to a search from the $C$ ambridge Structural Database that the frameworks of dihal oacenaphthene were planar and the frameworks of dihalonaphthene were not planar. The bond distances of Br1-C1 (1.91(3) A) and $B r 2-C 2$ (1.92(2) $\AA$ ) were within the expected theoretical $\mathrm{Br}-\mathrm{C}$ distance of $1.94 \AA$, but they were longer than that of $1.893 \AA$ in 5-bromo, 6-chloroacenaphthene. ${ }^{10}$ The bridging ethano carbon atoms (C11 and C12) also lay in the naphthalene plane with the $\mathrm{C} 11$ and $\mathrm{C} 12$ deviations of 0.12 (3) $\AA$ and 0.12 (3) $\AA$, respectively, and C4-C11-C 12-C5 torsion angle of $1(3)^{\circ}$.

Using the lastest version 5.12 of Cambridge Structural Database (CSD) ${ }^{4}$, a survey of crystal structures of 5,6-dihaloacenaphthene revealed that

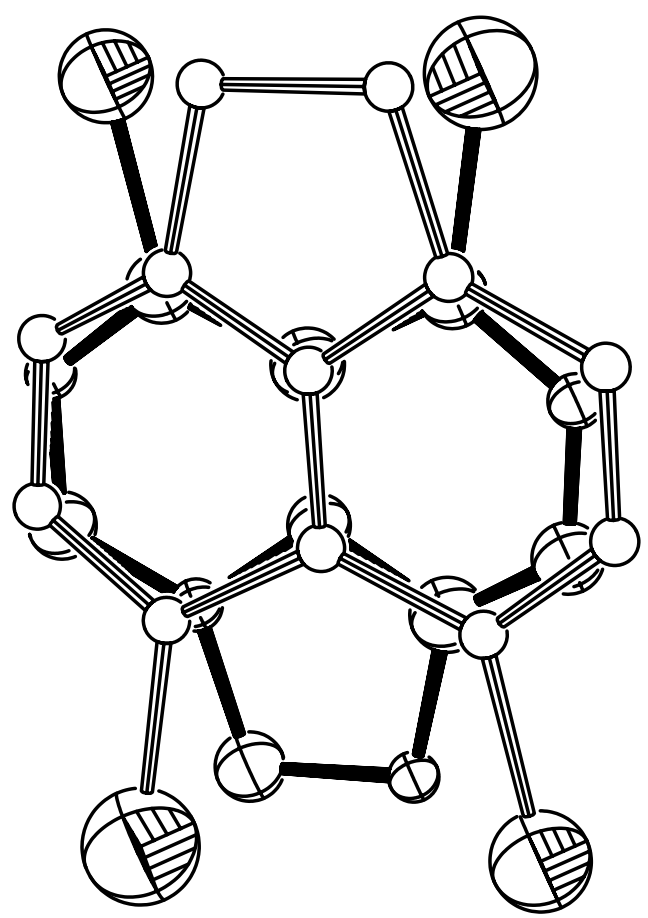

Fig 4. A p-p stacked pair of 5,6-dibromoacenaphthene. 
the molecules prefer to stack laterally in a dimerpairwise mode. This is probably due to the minimization of the repulsive force between the hal ogen atoms and between the ethylene bridges. When comparing between 1 and 5,6-dichloroacenaphthene ${ }^{12}$, it can be seen that even though $\mathbf{1}$ is overcrowded with the bromine atoms, the acenaphthalene frameworks are packed in an unexpected straight dimer-pairwise of a herringbone type (Fig 3). The acenaphthalene planes are found in centrosymmetrically related pairs and parallel to one another by $\pi$ - $\pi$ interactions (Fig 4 ) with the interplanar distance of 3.57(9) $\AA$, and the distance between their centroids [CT01...CT01 $(-x,-y,-z)=3.91(2) \AA]$.

\section{ACKNOWEDGement}

I am grateful to Dr M Watkinson and Dr RG Prichard for providing the 5,6-dibromoacenaphthalene. The financial support for this research was provided by the National Science and Technology Devel opment Agency (NSTDA) to N ongnuj Jaiboon (CO-B-06-33-09-201). I wish to thank Dr Veera Muangsin and Dr Thawatchai Tuntulani for kind suggestions and reading of the manuscript.

\section{Rererences}

1. Harris KDM and Tremayne M (1996) Crystal structure determination from powder diffraction data. Chem $M$ ater $\mathbf{8}$, 2554-70.

2. Wessels T, Baerlocher C and McCusker LB (2000) Singlecrystal-like diffraction data from polycrystalline meterials. Science 284, 5413, 477-9.

3. Reviews in Mineralogy (1989), The Mineralogical Society of America, Wahington DC, Vol 20.

4. The Cambridge Structural Database (CSD) (2000), Cambridge Crystallographic Data Centre, Cambridge, UK.

5. Werner PE, Erikson L and Westdahl M (1985) TREOR, a semiexhaustive trial-and-error powder indexing program for all symmetries. J Appl Cryst 48, 367.

6. Rodriguez-Carvaj J, "FULLPROF program", In: Collected Abstracts of Powder Diffraction M eeting: Toulouse, France, July, 1990, 127.

7. Thompson $P, C$ ox DE, Hastings JB, (1987). Rietveld refinement of Debye-Scherrer synchrotron X-ray data from $\mathrm{Al}_{2} \mathrm{O}_{3}$. J Appl Cryst 20, 79.

8. Le Bail A, Duroy H, Forquet JL (1988) Ab initio structure determination of $\mathrm{LiSbWO}_{6}$ by X-ray powder diffraction. Mater Res Bull 23, 447.

9. Sheldrick GM (1997) SHELX-97, University of Gottingen, Germany.

10. Avoyan RL, Struchkov YT (1961) Zh Strukt K him 5, 407, 1964.

11. Avoyan RL, Struchkov YT (1961) Zh Strukt Khim 2, 719.

12.J ohnson CK and Bernett MN (1996) ORTEP-3 for Windows, University of Glasgow, UK. 